\title{
The Use of Silicone Drainage Tubing to Control Post-Keratoplasty Glaucoma
}

\author{
COLIN M. KIRKNESS, YVONNE LING and NOEL S. C. RICE
}

London

\begin{abstract}
Summary:
A series of 20 patients who developed severe post-keratoplasty glaucoma unresponsive to medical therapy and trabeculecetomy were treated using silicone drainage tubing and an anterior encircling gutter. The results indicate a four year probability of maintaining vision and normal intraocular pressure $(<21 \mathrm{mmHg})$ of 0.68 . In contrast, an earlier series of 13 patients receiving cycloablation with cryotherapy did significantly worse.
\end{abstract}

The development of glaucoma following keratoplasty is by no means an uncommon complication and may be particularly likely in aphakic grafts and in eyes with pre-existing glaucoma. ${ }^{1}$ The management of such glaucoma is frought with difficulties, particularly when medical therapy fails. Laser trabeculoplasty has not been widely used; it is unlikely to prove suitable in cases where there is disorganisation of the drainage angle. Trabeculectomy is still the most commonly used surgical procedure once medical therapy has become inadequate but no data exist as to the its success in post-keratoplasty glaucoma. Where there is conjunctival scarring, on general principles, the success of drainage surgery can be expected to be poor.

In these difficult situations, further surgical options are limited. Casey has shown that cyclodialysis is unlikely to control pressure satisfactorily. $^{2}$ Cyclocryotherapy has been recommended $^{3}$ but it is an uncontrolled procedure and its use may predispose to graft failure, cystoid macular oedema and even phthisis bulbi. Nevertheless, the technique has been employed for several years when all else has failed to control intra-ocular pressure in advanced cases.
Considerable interest has arisen in recent years in the use of silicone drainage tubes as first recommended by $\mathrm{Molteno}^{4}$ and then later modified by Schocket ${ }^{5}$ who described the tube draining to an anterior, encircling, inverted, silicone gutter. Molteno later adopted a two-stage technique in order to alleviate the problem of prolonged hypotony and the risk of expulsive haemorrhage,${ }^{6,7}$ to which many aphakic or vitrectomised eyes are prone.

The use of silicone drainage tubes in post keratoplasty glaucoma has already been described in a small preliminary report ${ }^{8}$ This larger review of the problem seeks to establish the place of drainage tubes in the management of post-keratoplasty glaucoma (PKPG) and the likely complications which may be encountered. By way of comparison, a series of patients undergoing cyclocryotheraphy for PKPG is also discussed.

\section{Materials and Method.}

Tubes

The patients reported form a consecutive series of cases under the care of the surgeons in the Corneal Clinic, Moorfields Eye Hospital although the majority of the surgery has

Correspondence to: Colin M Kirkness, FRCS, Dept of Clinical Ophthalmology, Institute of Ophthalmology , Moorfields Eye Hospital, City Road, London EC1V 2PD.

Presented at the Annual Congress Ophthalmological Society of the United Kingdom, April 1988. 
been performed by one of us (CMK). All patients have been followed prospectively and none has been lost to follow-up, which averages 26 months, range $6-60$ months. All patients were already aphakic by the time the tubes were inserted and most had had at least a partial anterior vitrectromy. All had had at least one previous surgical attempt at control of intraocular pressure, usually by trabeculectomy, before a tube was considered. The number of prior intraocular procedures ranged from 2 to 9 , per eye, mean 5.3. Table I shows the original diagnoses for the patients in this group.

The surgical procedure used most often, i.e. in the later patients in the series, is divided into 2 stages separated by approximately 6 to 8 weeks. At the first stage, a wide conjunctival incision - at least $6 \mathrm{~mm}$ behind the limbus - is made, not a peritomy. The eye is encircled with an inverted 220 silicone gutter, which is attached to the sclera just behind the insertion of the rectus muscles. The silicone tube is inserted under the gutter through one quadrant. It is attached by $10 / 0$ nylon. The tube has $0.3 \mathrm{~mm}$ internal diameter and 0.64 external diameter (602-105 Dow Corning). The free end is buried in a small flap of sclera. (Fig $1 \mathrm{a}-\mathrm{d}$ ) If the intraocular pressure is greatly elevated and further damage to the optic nerve head is feared then at this time a trabeculectomy may be performed, which may help reduce the pressure

Table 1 The original diagnosis of those patients eventually receiving tubes or cyclocryotherapy.

\begin{tabular}{ll}
\hline Diagnosis & $\begin{array}{l}\text { Numberofpatients } \\
\text { Tube Cyclocryo }\end{array}$
\end{tabular}

\begin{tabular}{lll}
\hline $\begin{array}{l}\text { Anterior chamber } \\
\text { cleavage syndrome }\end{array}$ & 4 & 3 \\
Trauma & 1 & 4 \\
Suppurative keratitis & 1 & 2 \\
Herpes simplex keratitis & 1 & 1 \\
Chronic simple glaucoma & 3 & 1 \\
Congenital cataract & 2 & 1 \\
Bullous keratopathy & 2 & 1 \\
Uveitis & 2 & 0 \\
Keratoconus & 2 & 0 \\
Corneal melting & 1 & 0 \\
Neurofibromatosis & 1 & 0
\end{tabular}

temporarily until the second stage can be done. During the interim a fibro-vascular sheath forms around the gutter and this ultimately absorbs the aqueous draining through the tube. At the second stage, the conjunctiva is again opened carefully and the free end of the tube identified. A scleral flap 6 $\mathrm{mm}$ wide, extending back to the gutter and as deep as possible is raised. The free end of the tube is trimmed so that about $4 \mathrm{~mm}$ will extend into the anterior chamber. The anterior chamber is punctured with a 25 gauge knife and the tube inserted. Leakage of aqueous around the tube is minimal. The tube and scleral flap are secured with 10/0 nylon and the conjunctiva is carefully closed.

Postoperatively topical steroid drops, prednisolone $1 \%$, are administered 6 times/day to limit the possibility of graft rejection. An antibiotic drop is also given until the eye has healed.

\section{Cyclocryotherapy}

Patients attending the corneal clinic, who had had corneal grafts and required cyclocryotherapy between 1978 and 1985, were identified retrospectively. Cyclocryotherapy was administered in one or two sessions with a minimum of two quadrants and a maximum of four being ablated at any one time. The technique is the same as described by Binder. ${ }^{3}$ From Table I it can be seen that these patients were similar in their original diagnoses to those receiving tubes.

\section{Results}

Tubes

Twenty patients are reported. The indications for the original keratoplasty are shown in Table I. In the first six patients, in the series, a single stage procedure was performed. In all the later patients, the two stage procedure was undertaken. In every case the intraocular pressure was above 28 $\mathrm{mmHg}$ on maximum tolerable medical therapy, prior to insertion of the tube. In three patients, the insertion of the tube, at the second stage, was combined with keratoplasty. In 11 patients, the visual acuity has been maintained; in 2 , it has improved and in another 2, it improved following a 

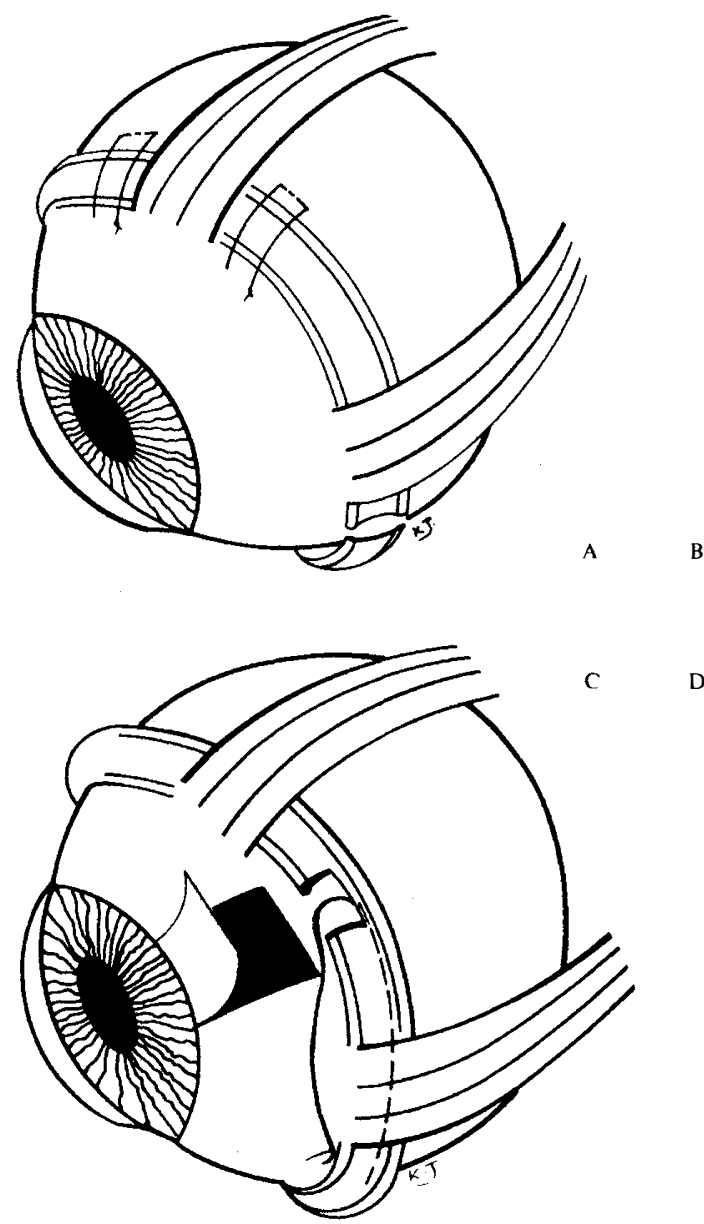
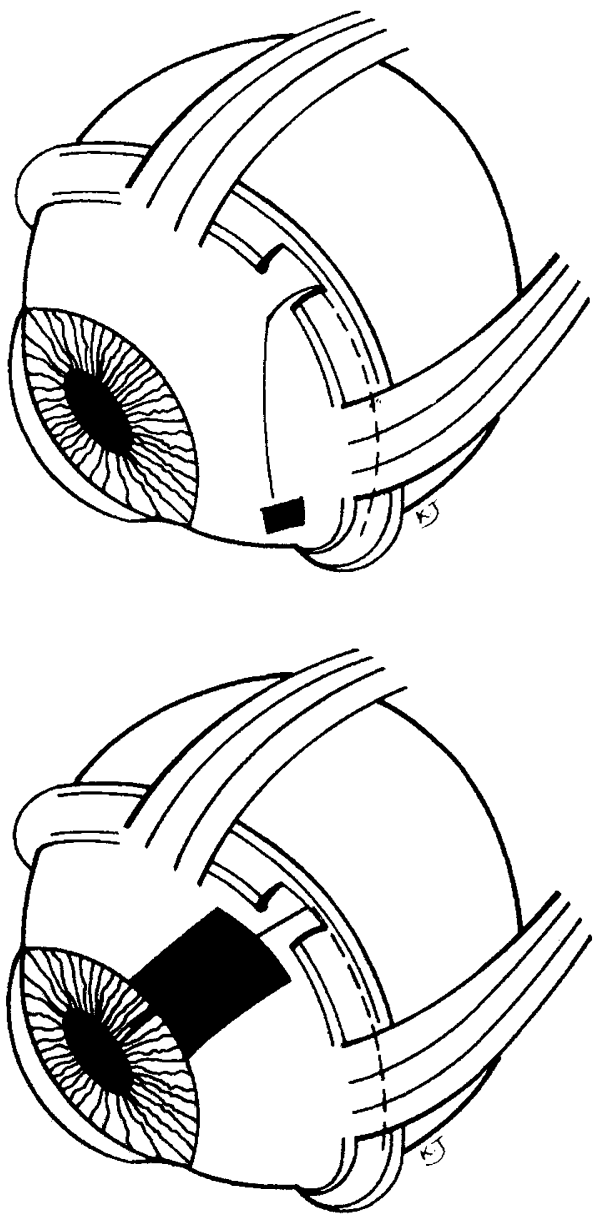

Fig. 1. A diagrammatic representation of the two-stage technique.

(A) Having opened the conjunctiva about $6 \mathrm{~mm}$ behind the limbus, the recti are identified and the 220 gutter inserted, encircling the eye. It is secured in place and the cut ends are also sutured together.

(B) A small section of the gutter is cut out to allow access for the tube so it may lie in the canal formed between the gutter and sclera without compression. It passes $90^{\circ}$ round the globe. It is secured in place with $10 / 0$ nylon. The free end is buried in a small scleral flap.

(C) Six weeks later the free end is identified and trimmed. The tube is flushed through to ensure patency. A large scleral flap $6 \times 8 \mathrm{~mm}$ and approximately $7 / 8 \mathrm{th}$ depth is raised. The anterior chamber is entered with a 25 gauge needle or knife.

(D) The flap is secured and the conjunctiva closed very carefully. About $4 \mathrm{~mm}$ of tube lies anterior to the iris in the anterior chamber.

further corneal graft. Vision has deteriorated in 5 patients. (Fig. 2)

The intra-ocular pressure has been maintained below $21 \mathrm{mmHg}$ in 16 patients; 9 require no antiglaucoma medication and 7 need some medical therapy but in each case less than the patient was taking preoperatively. (Fig. 3,4) In 2 patients, the pressure was not adequately controlled and subsequently the eyes received cyclocryotherapy. One eye had prolonged hypotony and is pre-phthisical. One eye had recurrent attacks of herpes simplex keratitis and was ultimately enucleated at another centre. The survival of a clear graft, with maintenance of vision and intraocular pres- 


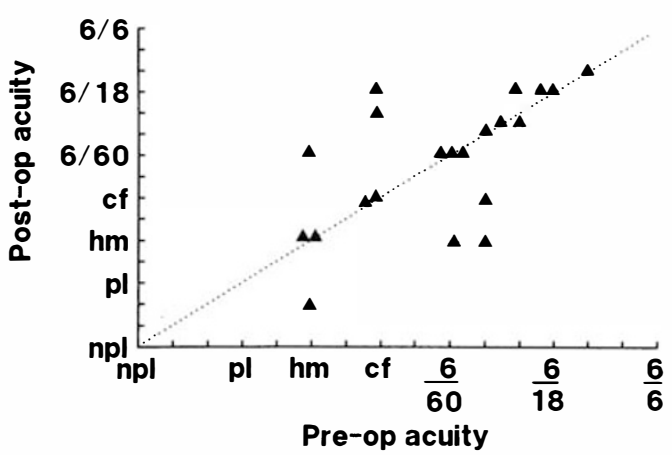

Fig. 2. A scattergran showing the change in vision before and after tube insertion. The post-operative vision is the latest available documentation.

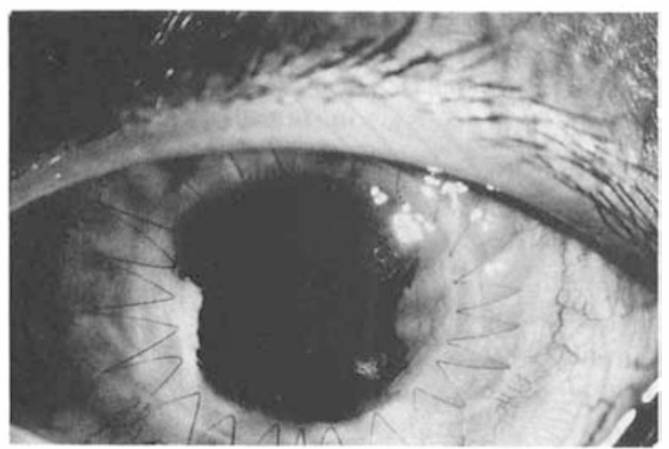

Fig. 3. A patient with bupthalmos, who underwent penetrating keratoplasty, intracapsular lens extraction and anterior vitrectomy. The intraocular pressure became uncontrolled even after trabeculectomy.

sure less than $21 \mathrm{mmHg}$ is shown for all eyes in the form of a Kaplan-Meier curve in Fig. 5a. ${ }^{9}$ Fig. 5b shows the survival of one stage tube versus two stage. The two stage is superior at a significance of $\mathrm{p}=0.15$ according to the method of Gehan. ${ }^{10}$ The mean pressure pre-operatively was $35.8 \mathrm{mmHg}$ and this dropped to below $20 \mathrm{mmHg}$ throughout the follow-up period. The graph of IOP with time is shown in Fig. 6.

\section{Complications.}

The most serious complication encountered was of severe exudative uveitic reaction which occurred in 3 patients, all of whom had had previous cyclocryotherapy. One of these had, in addition, a delayed suprachoroidal

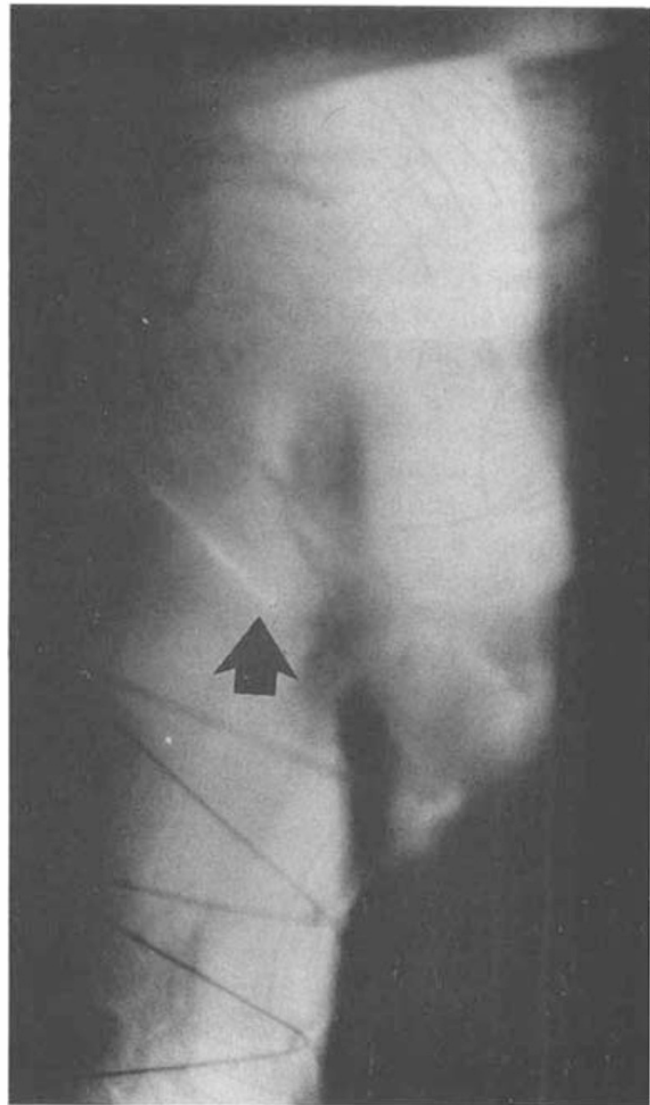

Fig. 4. The same patient as Figure 3 in close up to show the distal end of the tube, just visible behind the host side of the graft - host interface. The photograph was taken about 1 month after tube insertion.

haemorrhage. In 2 cases, the eyes settled after a prolonged period, the other remains hypotonic, as described above. Tube blockage at the internal opening with residual vitreous gel was found in 4 patients. In all cases this was unblocked satisfactorily with restoration of normal intraocular pressure by using an ocutome. Rejection episodes were encountered in the first 3 patients in the series. At this point, the high-dose, topical steroid regime was instituted.

In all, 4 corneas decompensated, but 2 already were showing signs of decompensation before tube insertion. Two have been regrafted with improvement of vision. Several eyes had multiple complications, but eleven had an uncomplicated progress. (Fig. 7) 

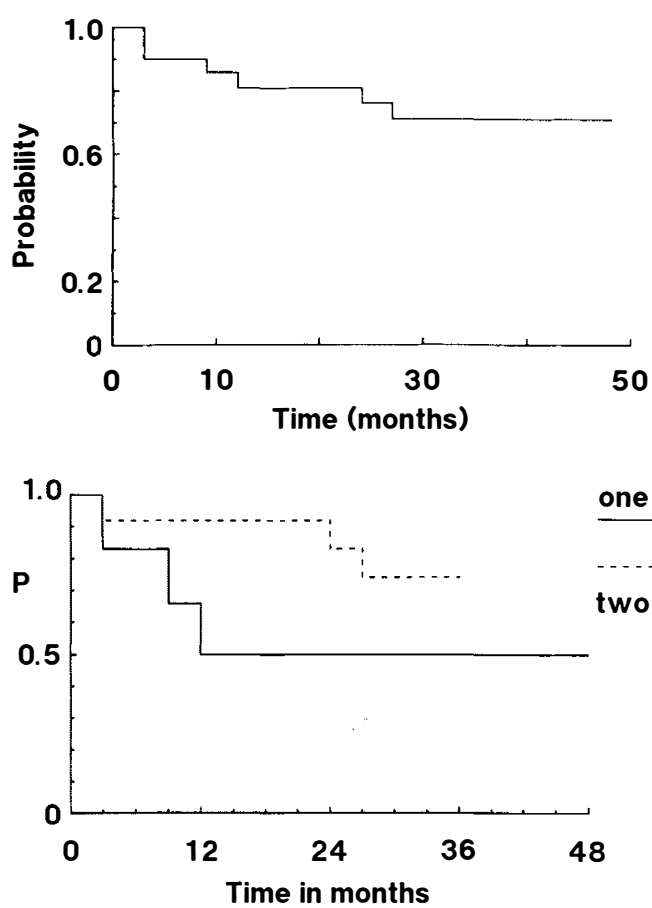

Fig. 5a. The probability of maintenance of a clear graft and $I O P<21 \mathrm{mmHg}$ with time, after tube insertion. (b) The survival segregated according to whether a one or two-stage procedure had been performed.

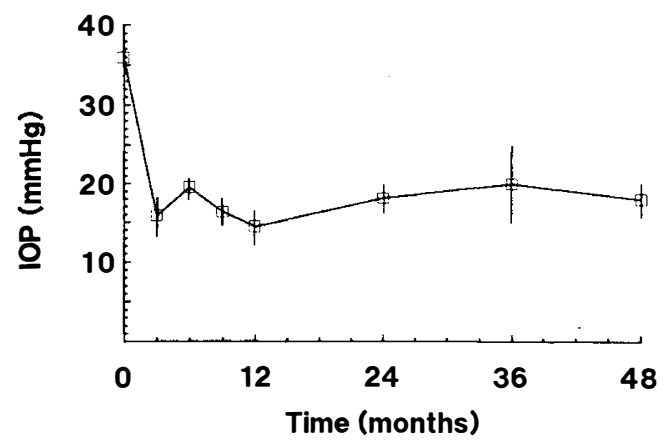

Fig. 6. The mean drop of IOP, following tube insertion, from time 0 (pre-operative value). Values are plotted \pm 2 standard errors.

\section{Cyclocryotherapy}

Thirteen patients were identified during the 7 year period up to 1985 . All had at least $180^{\circ}$ of ciliary body ablated. In five, the pressure was not controlled at all. In five more, the

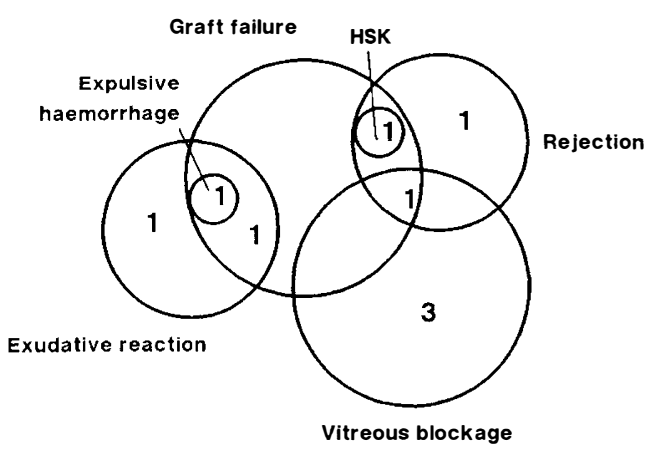

Fig. 7. Venn diagram showing the complications, after tube insertion. Fifteen serious complications occurred but only in 9 patients since some had multiple events.

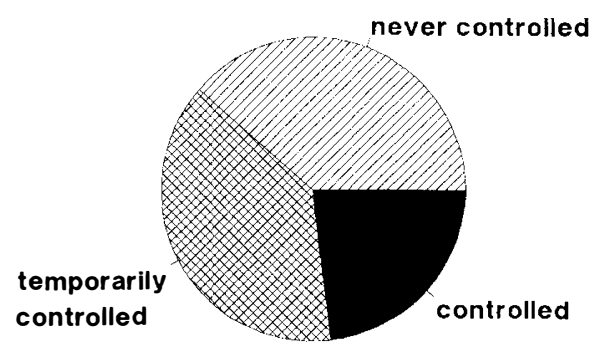

$N=13$

Fig. 8. A pie chart showing the relative success of cyclocryotherapy.

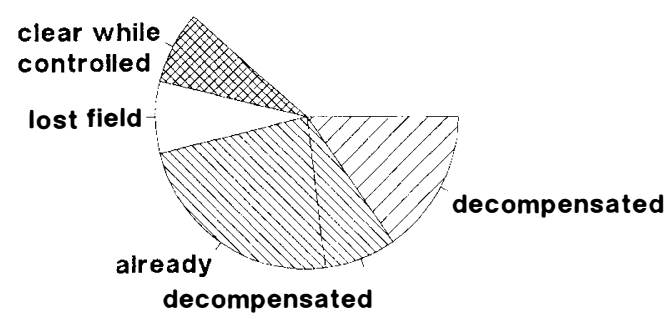

Fig. 9. In those 8 patients in whom there was (some) control of intraocular pressure, the pie chart shows the various complications. The position of each patient is consistant between figures 8 and 9 .

pressure was controlled for less than 2 years, and, in the remaining three, the intraocular pressure remained controlled at latest review. The visual outcome in these patients is shown diagrammatically in Figures 8 and 9. 
A comparative Kaplan-Meier curve for the two procedures, tubes or cyclocryo, is shown in Figure 10. The "tube" series is significantly better on Gehan analysis of the data at a level of significance, $\mathrm{p}=0.05$.

Complications were common in the cyclocryotherapy group. Apart from failure of the procedure to control the intraocular pressure,$^{10}$ one more lost field while intraocular pressure was normal, 4 corneas decompensated, and there were two retinal detachments. Ultimately no eye kept both a clear graft and normal intraocular pressure, in this group.

\section{Discussion}

The use of silicone drainage tubing to control difficult glaucoma is now established. There are many descriptions of different designs but the basic mechanism of action is similar. The tube provides an non-stenosing, non-healing permanent fistula from the eye through which aqueous drains. In the orbit, a fibrovascular sheath forms around the footplate, whether it is an acrylic plate described by Molteno ${ }^{4}$ or an encircling gutter as first described by Schocket..$^{5}$ The differences are likely to be related only to the surface area of the sheath. Molteno has recommended a complicated and potentially toxic drug regime to limit the amount and maturation of fibrosis taking place around the footplate. ${ }^{4.6}$ The larger surface area available with encircling gutter avoids the need to use such toxic drugs. Although a 220 gutter was used in this series, even wider gutters are manufactured for retinal detachment procedures and they could be used when an even larger surface area seems advisable.

To avoid problems associated with prolonged hypotony, several descriptions have appeared of tubes with a valve like function, so that at low pressures excess aqueous does not drain. ${ }^{11}$ Despite the elegance of this idea, they have not found widespread use. Molteno suggested that a two stage procedure was more practicable, since by the time the second stage was performed there was sufficient sheath formed around the footplate to provide some resistance to outflow from the eye. ${ }^{6}$

Kirkness was the first to report the use of a

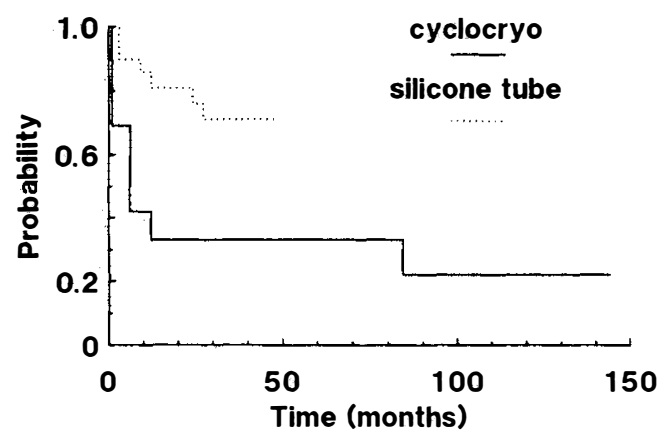

Fig. 10. The probability of maintenance of pre-op graft status and normal intraocular pressure with time comparing cyclocryotherapy and all tubes. This allows inclusion of those patients undergoing cyclocryo who had decompensated grafts. The longer follow-up is evident for the cyclocryotherapy group but there is significant difference between the 2 groups at $p=0.05$ (Gehan).

two stage Schocket-type tube and gutter, but, in the early report, the follow-up was short and the series small. ${ }^{8}$ This series suggests not only that silicone drainage tubing is of value in the management of PKPG but that the two-stage p ocedure may be superior. Although the numbers are small and obtaining statistical significance is difficult the strong trend $(p=0.15)$ towards the superiority of the two-stage procedure is clear.

In this series, a number of complications were encountered. Initially it was not appreciated that the tube might act as an additional limb of the "graft rejection arc", 12 and the first three patients all developed rejection episodes, only one of which reversed. It was interesting to note that a tidal flow of cells could be observed in and out of the tube. Since that time a high dose topical steroid regime has been employed (Guttae prednisolone 1\%, six times per day) and no further rejection episodes have been observed. The steroid could, in addition, have some beneficial effect on the degree of fibrosis around the tube, but this is unproven. Tube blockage with residual vitreous gel remains a problem, since many eyes will only have had "open sky" anterior vitrectomy or core vitrectomy previously, possibly leaving the posterior vitreous undetached. In eyes, which may be expected to develop 
severe pressure problems, it is suggested that as full a vitrectomy as possible be performed in aphakic patients at the time of keratoplasty.

The three eyes in the series which developed severe exudative uveitic reaction all had had previous extensive cyclocryotherapy, involving $360^{\circ}$ of the ciliary body. Although the intraocular pressure had not been controlled by this treatment, it may have prejudiced the eye when a good outflow was established by the tube by predisposing the eye to hypotony and relative ischaemia. Although 2 eyes recovered slowly, the complication suggests that previous cyclocryotherapy should be regarded, at least, as a relative, contraindication to tube insertion.

The need for high dose topical steroids in the long term suggests that great caution should be used if the eye has a history of herpetic infection.

Although it is impossible to produce a perfectly matched, randomised parallel series for the cyclo-ablative procedure, the similarities of the patients in the two groups are quite close. In each the procedure was only used after more conventional techniques had failed. All eyes had had extensive previous surgery and all were aphakic. The series contrasts greatly to others published, particularly that of Binder ${ }^{3}$ where cycloablation was used as the treatment of choice once medical therapy had failed in post-keratoplasty glaucoma. The follow-up in that series was quite short - maximum 50 months and no survival data were presented. Nevertheless, many eyes appeared to do well. The eyclocryo series reported in this paper has long follow-up and is disappointing in its implications. Even on the basis of the small numbers, one must conclude that cyclocryotherapy cannot be used when it is hoped to retain useful vision in a grafted eye.

The technique of handling censored data, that is data from patients who have been followed for different periods of time and with different starting points into the study, has been established by Kaplan and Meier. ${ }^{9}$ Statistical comparison between two cohorts receiving different treatment regimes even if the data is censored can be done using an analytical procedure devised by Gehan. ${ }^{10} \mathrm{Ap}$ - plying these methods to the two series described, the tube series is statistically superior at a two-tailed $p$ value of 0.05 . Our results suggest that when medical therapy and trabeculectomy fail to control postkeratoplasty glaucoma, silicone drainage tubing, preferably in a two stage procedure, should be used to control intraocular pressure and maintain vision. It has a probability of 0.68 of success, at four years. Cyclocryotherapy should be reserved for those eyes where maintenance of visual potential is not important.

This paper was presented as a video at the Ophthalmological Society of the United Kingdom Annual Congress. We wish to thank Mr Alan Lacey for his invaluable help and skill in preparing the videotape.

\section{References}

${ }^{1}$ Kirkness CM, Moshegov A: Post keratoplasty glaucoma. (submitted).

${ }^{2}$ Casey TA, Gibbs D: Complications in corneal grafting. Trans Ophthalmol Soc UK 1972; 86: 517-30.

${ }^{3}$ Binder PS, Abel R, Kaufman HE: Cyclocryotherapy for glaucoma after penetrating keratoplasty. Am J Ophthalmol 1975; 79: 48992.

${ }^{4}$ Molteno ACB: A new implant for glaucoma clinical trial. Br J Ophthalmol 1969; 53: 60615.

${ }^{5}$ Schocket SS, Lakhanpal V, Richards RD: Anterior chamber tube shunts to an encircling band in the treatment of neaovascular glaucoma. Ophthalmology 1982; 89; 1188-94.

${ }^{6}$ Molteno ACB, Ancker E, van Biljon G: Surgical technique for advanced juvenile glaucoma. Arch Ophthalmol 1984; 102: 51-7.

${ }^{7}$ Canning CR, Lavin M, McCartney ACE, Hitchings RA, Gregor Z. Suprachoroidal haemorrhage following drainage procedures. (submitted).

${ }^{8}$ Kirkness CM: Penetrating keratoplasty, glaucoma and silicone drainage tubing. Developments in Ophthalmology (Karger, Basel) 1987; 14: 161-5.

${ }^{9}$ Kaplan E, Meier P: Nonparametric estimation from incomplete observations. J Am Statist Ass 1958; 53: 457-81.

${ }^{10}$ Gehan EA: A generalised Wilcoxon test for comparing arbitarily singly censored samples. Biometrika 1965; 52: 202-3. 
11 Krupin T, Podos SM, Becker B, Newkirk JB: Valve implants in filtering surgery. $A m J$ Ophthalmol 1976; 81: 232-5.

12 Jones BR: Present knowledge and problems of corneal graft failure. in: Corneal Graft Failure, Ciba Symposium 15, Elsevier Associated scientific publishers, Amsterdam 1973, p34954. 